\title{
ARTIFICIAL MINI-MAGNETOSPHERE AS A MEANS OF CONTROLLING SPACECRAFT MOTION IN THE EARTH IONOSPHERE
}

\author{
Institute of Technical Mechanics \\ of the National Academy of Sciences of Ukraine and the State Space Agency of Ukraine \\ 15 Leshko-Popel St., 49005, Dnipro,Ukraine; e-mail: yu.kuchugurnyi@gmail.com
}

Based on the results of a series of experimental studies of the interaction of spacecraft models with a hypersonic rarefied plasma flow, this paper demonstrates the possibility of controlling spacecraft motion in the ionosphere with the use of a device of the "magnetic sail" type and proposes an idea of an experiment onboard a CubeSat microsatellite in a near-Earth orbit. If a spacecraft is equipped with a source of a strong magnetic field, then in a hypersonic rarefied plasma flow a nonuniform plasma structure called an artificial mini-magnetosphere, which is similar to a planetary magnetosphere, will form in the vicinity of the spacecraft. In this case, part of the plasma flow momentum will be transferred to the magnetic field source, thus resulting in additional forces acting on the spacecraft. This principle forms the basis for the "magnetic sail" - a jetless magnetohydrodynamic propulsion unit that uses the kinetic energy of the solar wind. Experimental studies of the interaction of spacecraft models with a plasma beam were conducted on a plasmaelectrodynamic setup. The drag and lift acting on the models were determined as a function of the flow parameters and the magnetic field. It was shown that an artificial minimagnetosphere may be an effective means of controlling spacecraft motion in the Earth ionosphere. The experiment to be conducted in near-Earth space envisages equipping a microsatellite with permanent magnets encased in a controllable enclosure that shields the magnetic field and determining the satellite orbit variations after removing the shield as a function of the magnetic field parameters. The experiment might be a first verification of the concept of the "magnetic sail" as a spacecraft propulsion unit. Controlling the motion of a "magnetized" body by using the long-term interaction of the body's magnetic field with the ionospheric plasma may be the key component of a radically new technology for space debris removal from the ionosphere.

Keywords spacecraft, CubeSat, YuzhSat, ionosphere, mini-magnetosphere, plasma, magnetic sail, solar wind, physical simulation, plasmaelectrodynamic setup.

1. Parker E. Solar wind (in Russian). Uspekhi Fizicheskikh Nauk. 1964. V. 84, No. 1. Pp. 169 - 182.

2. Model of Space. In two volumes. V. 1 Physical Conditions in Space (in Russian) / M. I. Panasyuk, L. S. Novikov (Eds.) . - Edition 8. - Moscow: Knizhny Dom Universitet, 2007. - 872 pp.

3. Zubrin R. M., Andrews D. G. Magnetic sails and interplanetary travel. Journal of Spacecraft and Rockets. 1991. V. 28, No. 2. Pp. 197-203.

4. Winglee R. M.m Slough J.,Ziemba T.,Goodson A. Mini-magnetospheric plasma propulsion: Tapping the energy of the solar wind for spacecraft propulsion. Journal of Geophysical Research. 2000. V. 105, No. A9. Pp. $21067-21077$.

5. Janhunen P. Electric sail for spacecraft propulsion. Journal of Propulsion and Power. 2004. V. 20, No. 4. Pp. $763-764$

6. Laboratoty experiments with a terrella: the effect of kinetic scales on physical similarity to planetary magnetospheres (in Russian) V.M.Antonov, E. L. Boyarintsev, Yu. P. Zakharov, A. V. Melekhov, V. G. Posukh, A. G. Ponomarenko, I. F. Shaikhislamov // Modern Advances in Plasma Heliogeophisics / L. M. Zeleny, A. A. Petrukovich, I. S. Veselovsky (Eds.) - Moscow : Space Research Institute of the Russian Academy of Sciences, 2016. 672 pp. Pp. 383 - 406.

7. Bamford R., Gibson K. J., Thornton A. J., Bradford J. et al. The interaction of a flowing plasma with a dipole magnetic field: measurements and modelling of a diamagnetic cavity relevant to spacecraft protection. Plasma Phys. Control. Fusion. 2008. V. 50, No. 12. Art. 124025 (11pp).

8. Bityurin V. A., Bocharov A. N. On ground magnetohydrodynamic experiments in hypersonic flows (in Russian). Teplofizika Vysokikh Temperatur. 2010. V. 48, No. 6. Pp. 916-923.

9. Shuvalov V.A., Tokmak N. A., Pis'mennyi N. I., Kochubei G. S. Control of the dynamic interaction of a "magnetized" sphere with a hypersonic flow of rarefied plasma. High Temperature. 2015. V. 53, No. 4. p. 463 -469 .

10. Shuvalov V. A., Tokmak N. A., Pis'mennyi N. I., Kochubei G. S. Dynamic interaction of a magnetized solid body with a rarefied plasma flow. Journal of Applied Mechanics and Technical Physics. 2016. V 57, No. 1. Pp. $145-152$.

11. Shuvalov V. A., Kochubei G. S., Lazuchenkov D. N. Intreaction of spsacecraft with plasma flows and electromagnetic radiation in the Earth atmosphere (in Russian). Tekhnicheskaya Mekhanika. 2015. No. 4. Pp. 117 125 .

12. V. A. Shuvalov, Kulagin S. N., Kochubei G. S., Tokmak A. A. Physical simulation of the interaction effects of magnetized bodies and the Earth's atmosphere in a hypersonic rarefied plasma flow. High Temperature. 2012. V. 50, No. 3. Pp.. $315-322$.

13. Tokmak N. A., Kuchugurnyi Yu. P., Kochubei G. S., Tsokur A. G. Mini-magnetosphere as a means of spacecraft control in the Earth atmosphere (in Russian). $17^{\text {th }}$ Ukrainian Conference on Space Research (Odesa, Au- 
gust 21-25, 2017). Abstracts. Kyiv : Space Research Institute of the National Academy of Sciences of Ukraine and the State Space Agency of Ukraine, 2017. 232 pp. P. 223.

14. Shuvalov V. A., Kuchugurnyi Yu. P. Experimental validation of the concept of an artificial minimagnetosphere as a means of controlling spacecraft motion in the Earth ionosphere (in Russian). Kosmicheskaya Nauka I Tekhnologiya. 2018. No. 2. Pp. 43 - 46.

15. Shuvalov V. A., Gorev N. B., Kulagin S. N., Kuchugurnyi Yu. P. Braking of a space debris object in the Earth ionosphere using the object's magnetic field. Physical simulation (in Russian). Kosmicheskiye Issledovaniya (to be published).

16. Fujita K. Particle simulation of moderately-sized magnetic sail. Journal of Space Technology and Science. 2004. V. 20, No. 2. Pp. $26-31$.

17. Nishida A. Geomagnetic Diagnosis of the Magnetosphere (in Russian). Moscow : Mir, 1980. 302 pp.

18. Akasofu S. I., Chapman S. Solar Terrestrial Physics (in Russian). In 2 parts, Part 2. Moscow : Mir, 1975. $512 \mathrm{pp}$.

19. YuzhSat Microsatellite Platform Specifications. Provisions of the call for TuzhSat platform payload projects (in Ukrainian). 2017. Pp. 3-5. URL: http://space-conf.ikd.kiev.ua/conference/info (Call No. 2).

Received 21.05.2018,

in final form 19.06.2018 